\title{
Factors associated with delay in carotid endarterectomy for patients with symptomatic severe internal carotid artery stenosis: a case-control study
}

\author{
Daniel Meyer BSc, Erwin Karreman PhD, David Kopriva MDCM
}

Abstract

Background: The Canadian Best Practice Recommendations for Stroke Care (2008 update) recommend that patients with neurologic symptoms secondary to severe internal carotid artery stenosis undergo carotid endarterectomy within 14 days of symptom onset to prevent stroke. The purpose of this study was to identify patient and system factors associated with meeting, or failing to meet, the guideline.

Methods: In this case-control study, potential study participants were identified through an electronic search of the Discharge Abstract Database. We reviewed the charts of patients who presented to our centre with neurologic symptoms ipsilateral to internal carotid artery stenosis of $70 \%-99 \%$ and underwent carotid endarterectomy in our centre between Jan. 1, 2009, and Dec. 31, 2014. We performed logistic regression analysis to identify factors associated with meeting, or failing to meet, the guideline.

Results: Of the 412 patients who underwent carotid endarterectomy during the study period, 219 met the inclusion criteria. Sixtyseven patients (30.6\%) met the 14-day guideline. Thirty (14.2\%) of the 212 patients who could be classified as case or control subjects did not access the health care system within 14 days. Once in the health care system, failure to meet the guideline was associated with a presentation of amaurosis fugax (odds ratio [OR] 0.22, 95\% confidence interval [Cl] $0.05-0.96 \mathrm{compared}$ to completed minor stroke) and presentation to a nonemergency outpatient setting (OR 9.08, 95\% $\mathrm{Cl} 2.51-32.80$ compared to emergency department).

Interpretation: Improvements in meeting the goal of carotid endarterectomy within 14 days of symptom onset for severe internal carotid artery stenosis should be directed at patient and system factors. A system for rapid diagnosis and referral of symptomatic patients to an appropriate surgeon should be established.

arotid atherosclerosis is an important cause of stroke, ${ }^{1}$ which is a major cause of disability and death in Canada. ${ }^{2}$ The standard of care for patients with symptomatic ipsilateral severe (70\%-99\%) internal carotid artery stenosis includes carotid endarterectomy plus best medical therapy. ${ }^{3-5}$ Early after the first neurologic event, the patient is at high risk for further events. ${ }^{6,7}$ The risk of major stroke following transient ischemic attack or minor stroke is as high as $20 \%-30 \%$, and the risk of harm increases with delays in definitive treatment. ${ }^{6,8,9}$ This evidence forms the basis for surgical guidelines in the Canadian Best Practice Recommendations for Stroke Care (2008 update), which recommend that patients with symptomatic severe internal carotid artery stenosis should undergo carotid endarterectomy within 14 days of the index neurologic event to reduce the risk of major stroke. ${ }^{10}$

Despite evidence that early carotid endarterectomy following an index event reduces the risk of stroke significantly, less than half of patients presenting with symptomatic severe internal carotid artery stenosis have carotid endarterectomy performed within the recommended 14-day time frame. ${ }^{11-13}$ We conducted a study to determine the proportion of patients at our centre who have met the Canadian Best Practice Recommendations for Stroke Care and to define the factors associated with meeting, or failing to meet, the recommended care guideline.

\section{Methods}

\section{Setting}

All carotid endarterectomy procedures in our referral area of 450000 people in Saskatchewan and Manitoba were performed

Competing interests: None declared.

This article has been peer reviewed.

Correspondence to: David Kopriva, dkopriva@sasktel.net

CMAJ Open 2018. DOI:10.9778/cmajo.20170060 
at the Regina General Hospital by 3 vascular surgeons who used a common electronic medical record. No surgeons apart from those in this study performed carotid endarterectomy. Carotid stenting was not performed in our centre. For patients presenting with symptoms of transient ischemic attack, initial assessment was performed by primary care physicians in outpatient clinics or in an emergency department setting. Patients then followed divergent paths through the health care system, with some undergoing radiologic tests and others undergoing consultations with specialists before a referral was made for consideration of carotid endarterectomy (Figure 1).

\section{Design, participants and data collection}

This case-control study involved patients who underwent carotid endarterectomy between Jan. 1, 2009, and Dec. 31, 2014. We identified potential study participants through an electronic search of the Discharge Abstract Database using International Statistical Classification of Diseases and Related Health Problems, 10th revision, Canada (ICD-10-CA) codes 1.JE.57.* and 1.JE.87.* to identify all patients who underwent carotid surgery during the study period. We abstracted data for all study participants from the vascular surgeons' electronic medical record. Each patient's age, sex and location of residence were recorded. The type of neurologic event was categorized as motor, phasic or sensory transient ischemic attack, amaurosis fugax or completed minor stroke. We recorded the location and date of the initial contact with a health care practitioner, all investigations performed, all referrals sent by the first and each subsequent practitioner, the dates of surgical consultation and subsequent surgery.

This study included patients who presented with carotid territory neurologic dysfunction ipsilateral to internal carotid artery stenosis that was identified on preoperative imaging to be causing 70\%-99\% stenosis as described in the North American Symptomatic Carotid Endarterectomy Trial. ${ }^{3}$ Patients were also eligible for inclusion if preoperative imaging was reported with an appropriate descriptor such as "severe" or if they met ultrasonography velocity criteria for severe carotid stenosis. ${ }^{14} \mathrm{We}$ excluded patients who presented with asymptomatic carotid artery stenosis or moderate symptomatic stenosis $(50 \%-69 \%)$, underwent concurrent noncarotid surgery (e.g., cardiac), experienced the index neurologic event in hospital, had a severe, disabling stroke requiring neurologic recovery before surgery or underwent unrelated carotid artery surgery such as carotid body tumour resection, plication of a kinked carotid artery or repair of carotid aneurysmal disease.

Participants were categorized for analysis as control subjects if they received surgery within 14 days of the neurologic event and as case subjects if they failed to receive surgery within this time frame. The 14-day criterion reflected the Canadian Best Practice Recommendations for Stroke Care in effect during the study period. ${ }^{10}$ Although these practice guidelines have been updated with shorter treatment targets, ${ }^{15}$ the 2008 guidelines were in effect for the entire period of this study.

The total duration from the index event to surgery was divided into 3 periods defined as "wait 0 ," "wait 1 " and "wait 2" (Figure 1), similar to methodology used elsewhere. ${ }^{16}$ Wait 0 is the time from the neurologic event until the patient's first contact with the health care system, wait 1 is the time between first contact and the surgical assessment, and wait 2 encompasses the time between the surgical assessment and surgery.

\section{Statistical analysis}

This study included 219 cases. Power calculations indicated that a sample of 82 cases was required to detect a 30\% difference in mean time from neurologic event to surgery, with $80 \%$ probability and $95 \%$ confidence intervals. Our study is therefore well powered to identify factors associated with delays in care delivery. We estimated missing data elements by multiple imputation.

Our data showed nonparametric distribution and unequal variance (Welch $t$ test, Mann-Whitney test). We used the Pearson $\chi^{2}$ test and the Fisher exact test to compare categorical variables. Logistic regression analysis compared the contribution of treating surgeon and patient age, sex, place of

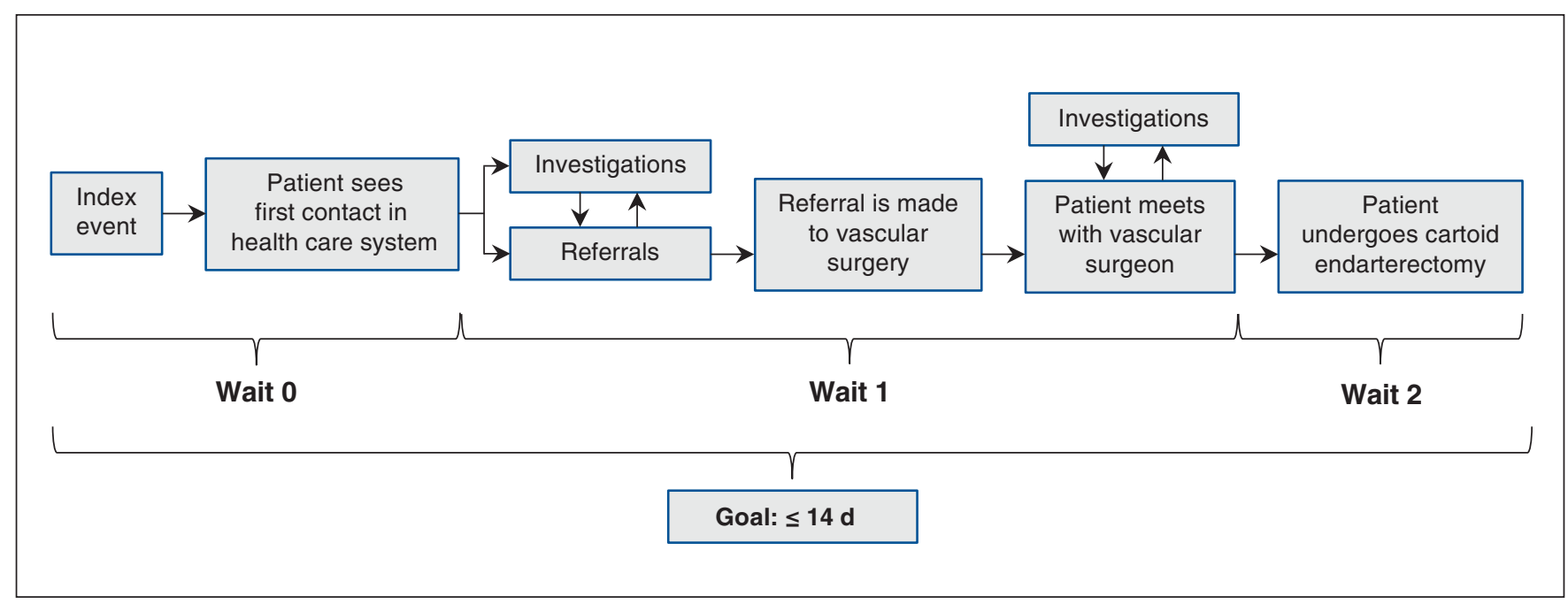

Figure 1: Duration of pathway from index event to carotid endarterectomy. 
residence, clinical setting at presentation and index neurologic event to differentiate between case and control subjects. We performed hierarchical logistic regression in 2 blocks. In the first block, the effect of the surgeon was considered. We chose the surgeon with the most cases as the base category to which the other surgeons were compared. In the second block, we compared patient age, sex, place of residence, clinical setting of presentation and index neurologic symptom. For comparison of index neurologic symptoms, we compared completed minor stroke with motor transient ischemic attack and amaurosis fugax.

We considered $p$ values $\leq 0.05$ statistically significant. We conducted statistical testing using SPSS version 22 (IBM Corporation).

\section{Ethics approval}

This study was approved by the Regina Qu'Appelle Health Region and the University of Saskatchewan research ethics boards through a harmonized review process. The requirement for individual informed consent was waived.

\section{Results}

A total of 412 patients underwent carotid endarterectomy during the study period, of whom 219 met the inclusion criteria (Figure 2). Demographic and clinical information for the study population is shown in Table 1 . The date of the index neurologic event could not be determined for 7 patients, who, therefore, could not be categorized as case or control subjects.
Sixty-seven participants (30.6\%) underwent carotid endarterectomy within 14 days of the index neurologic event. The median time from the index event to surgery was 28.5 days (interquartile range 12-28.5-79 d, mean 77.1 d). The median duration of wait 0 , wait 1 and wait 2 was 0 days (mean $23 \mathrm{~d}$ ), 8.5 days (mean $34 \mathrm{~d}$ ) and 7 days (mean $9 \mathrm{~d}$ ), respectively. For patients who presented to a nonemergency outpatient clinic, the median duration of wait 0 was 4 days, with a median of 47 additional days until surgery. For those who presented to an emergency department, the median duration of wait 0 was 0 days, with a median of 12 days until surgery.

The likelihood of presentation to an emergency department covaried by symptom type. Patients with hemispheric motor symptoms, phasic disturbance or completed minor strokes were more likely to present to an emergency department, whereas patients with more subtle symptoms such as sensory disturbance or amaurosis fugax presented more often to a nonemergency outpatient setting (Figure 3). The benefit of presenting to the emergency department was evident among patients with similar presentations. Among those with amaurosis fugax, only 2/22 (9\%) who presented to a nonemergency outpatient clinic met the 14-day guideline, compared to $7 / 10(70 \%)$ of those who presented to the emergency department (odds ratio [OR] 23.3, 95\% confidence interval [CI] 3.2-169.9). Among patients with minor stroke, 15/25 $(60 \%)$ of those who presented to the emergency department met the 14-day guideline, whereas neither of the 2 patients who presented to a nonemergency outpatient clinic met the guideline.

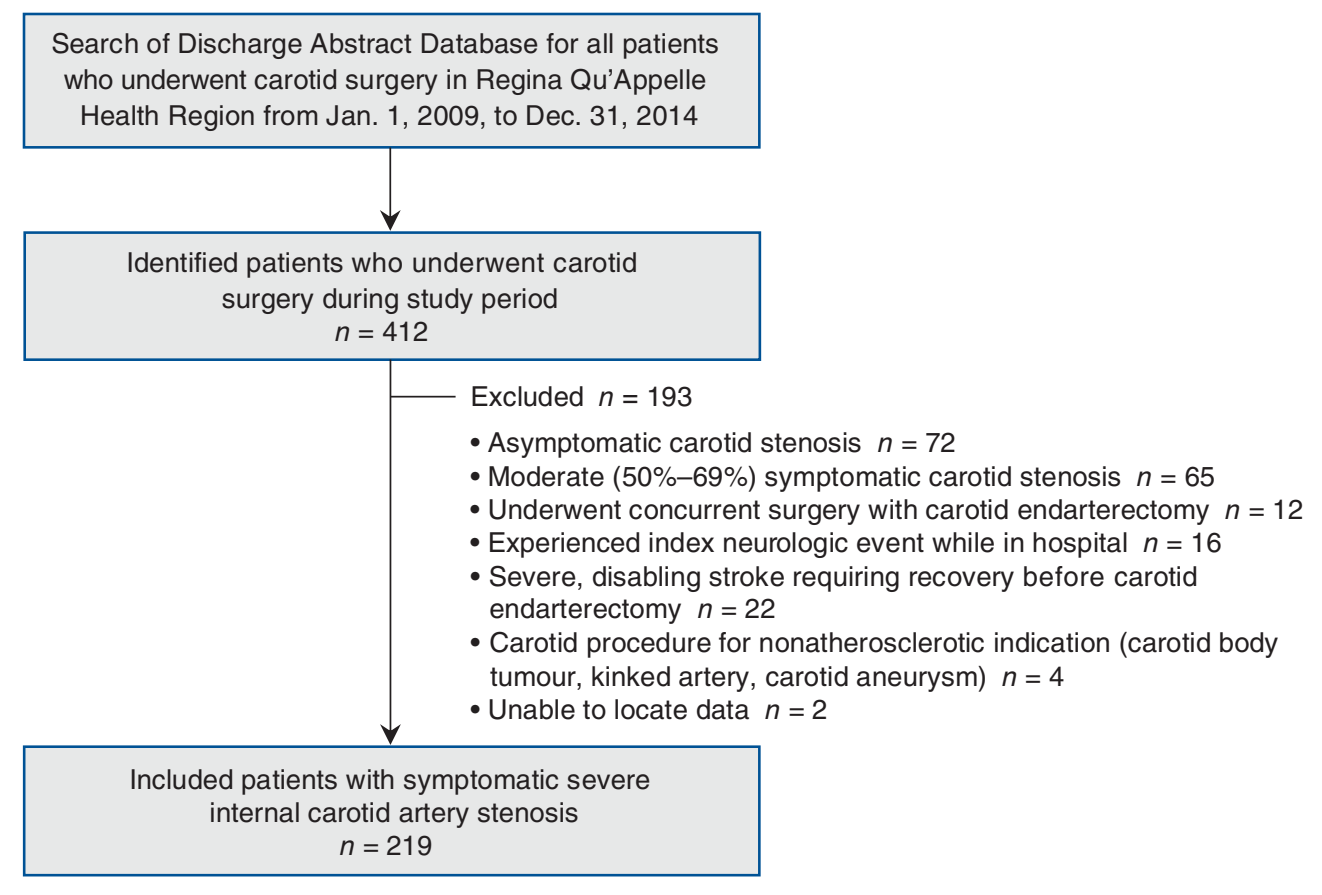

Figure 2: Flow diagram showing selection of study participants. 


\begin{tabular}{|c|c|c|c|}
\hline \multirow[b]{2}{*}{ Characteristic } & \multicolumn{3}{|c|}{ No. $(\%)$ of patients ${ }^{*} \dagger$} \\
\hline & $\begin{array}{c}\text { Total } \\
n=219\end{array}$ & $\begin{array}{l}\text { Case subjects } \\
\quad n=145\end{array}$ & $\begin{array}{c}\text { Control subjects } \\
\quad n=67\end{array}$ \\
\hline Male sex & $139(63.5)$ & $90(62.1)$ & $44(65.7)$ \\
\hline \multicolumn{4}{|l|}{ Age, mean \pm SE; yr } \\
\hline Overall & $72.1 \pm 0.6$ & $71.9 \pm 0.8$ & $72.9 \pm 1.2$ \\
\hline Male participants & $71.9 \pm 0.8$ & $71.0 \pm 1.0$ & $73.9 \pm 1.6$ \\
\hline Female participants & $72.4 \pm 0.9$ & $73.7 \pm 1.1$ & $68.9 \pm 1.6$ \\
\hline \multicolumn{4}{|l|}{$\begin{array}{l}\text { Lateralization of carotid } \\
\text { endarterectomy }\end{array}$} \\
\hline Right & $114(52.0)$ & $73(50.3)$ & $37(55.2)$ \\
\hline Left & $105(47.9)$ & $72(49.6)$ & $30(44.8)$ \\
\hline \multicolumn{4}{|l|}{ Place of residence } \\
\hline Regina & 88 (39.3) & $54(37.2)$ & $32(47.8)$ \\
\hline Outside Regina & $131(57.5)$ & $91(62.8)$ & $35(52.2)$ \\
\hline \multicolumn{4}{|l|}{ Index neurologic event } \\
\hline $\begin{array}{l}\text { Motor transient ischemic } \\
\text { attack }\end{array}$ & $78(35.2)$ & 49 (33.8) & $28(41.8)$ \\
\hline $\begin{array}{l}\text { Phasic transient ischemic } \\
\text { attack }\end{array}$ & $25(11.4)$ & $18(12.4)$ & $7(10.4)$ \\
\hline $\begin{array}{l}\text { Sensory transient ischemic } \\
\text { attack }\end{array}$ & $18(7.8)$ & $14(9.6)$ & $3(4.5)$ \\
\hline Amaurosis fugax & $66(28.3)$ & $53(36.6)$ & $9(13.4)$ \\
\hline Completed minor stroke & $32(14.2)$ & $11(7.6)$ & $20(29.8)$ \\
\hline \multicolumn{4}{|c|}{$\begin{array}{l}\text { Note: } \mathrm{SE} \text { = standard error. } \\
\text { *Except where noted otherwise. } \\
\text { tThe date of the index neurologic event could not be determined for } 7 \text { patients, who, therefore, could not be } \\
\text { categorized as case or control subjects. }\end{array}$} \\
\hline
\end{tabular}

Wait 0 duration was strongly associated with failing to meet the 14-day guideline $(p<0.001)$. Of the 212 patients who could be classified as case or control subjects, 30 (14.2\%) did not access health care services within 14 days of the index neurologic event. Wait 0 also covaried with the index symptom. Patients with amaurosis fugax presented to a practitioner after a median of 3 days, whereas those with hemispheric sensory symptoms presented after a median of 2 days. Those who presented with hemispheric symptoms resulting in phasic disturbance, motor deficit or completed minor stroke presented after a median of 0 days.

The symptom constituting the index neurologic event was associated with meeting the 14-day guideline (OR 13.4, 95\% CI 4.3-41.4). Patients who presented with a completed minor stroke were the most likely to meet the guideline, and those who presented with amaurosis fugax or purely sensory hemispheric symptoms were the least likely (Figure 4).

On logistic regression analysis, compared to presentation to an outpatient primary care setting, presentation to an emergency department was associated with a much higher chance of meeting the 14-day guideline for surgery (OR 9.08, 95\% CI 2.51-32.80) (Table 2). Patients with amaurosis fugax were less likely than those who presented with a completed minor stroke to meet the 14-day guideline (OR $0.22,95 \%$ CI 0.05-0.96).

Delayed surgery was associated with a greater number of physicians seen before surgical referral. Control subjects saw a mean of 1.97 practitioners, and case subjects saw a mean of 2.20 practitioners $(p<0.02)$. Twenty-eight patients saw 3 or more practitioners before surgical consultation. The number of consultants seen before surgery was not associated with the presenting symptom $(p=0.7)$. The most common referral from the first health care practitioner was to a neurologist (84 cases). Other services included ophthalmology (12), cardiology (3), internal medicine (11) and directly to vascular surgery (2).

The 2 most common actions taken by physicians in both the outpatient setting and the emergency department were referral for carotid duplex ultrasonography and referral to a neurologist. A median of 2 days elapsed from presentation to completion of carotid duplex ultrasonography in the emergency department, but a median of 8 days elapsed in a nonemergency outpatient clinic setting $(p<0.001)$. The median time from initial presentation to neurology consultation was 


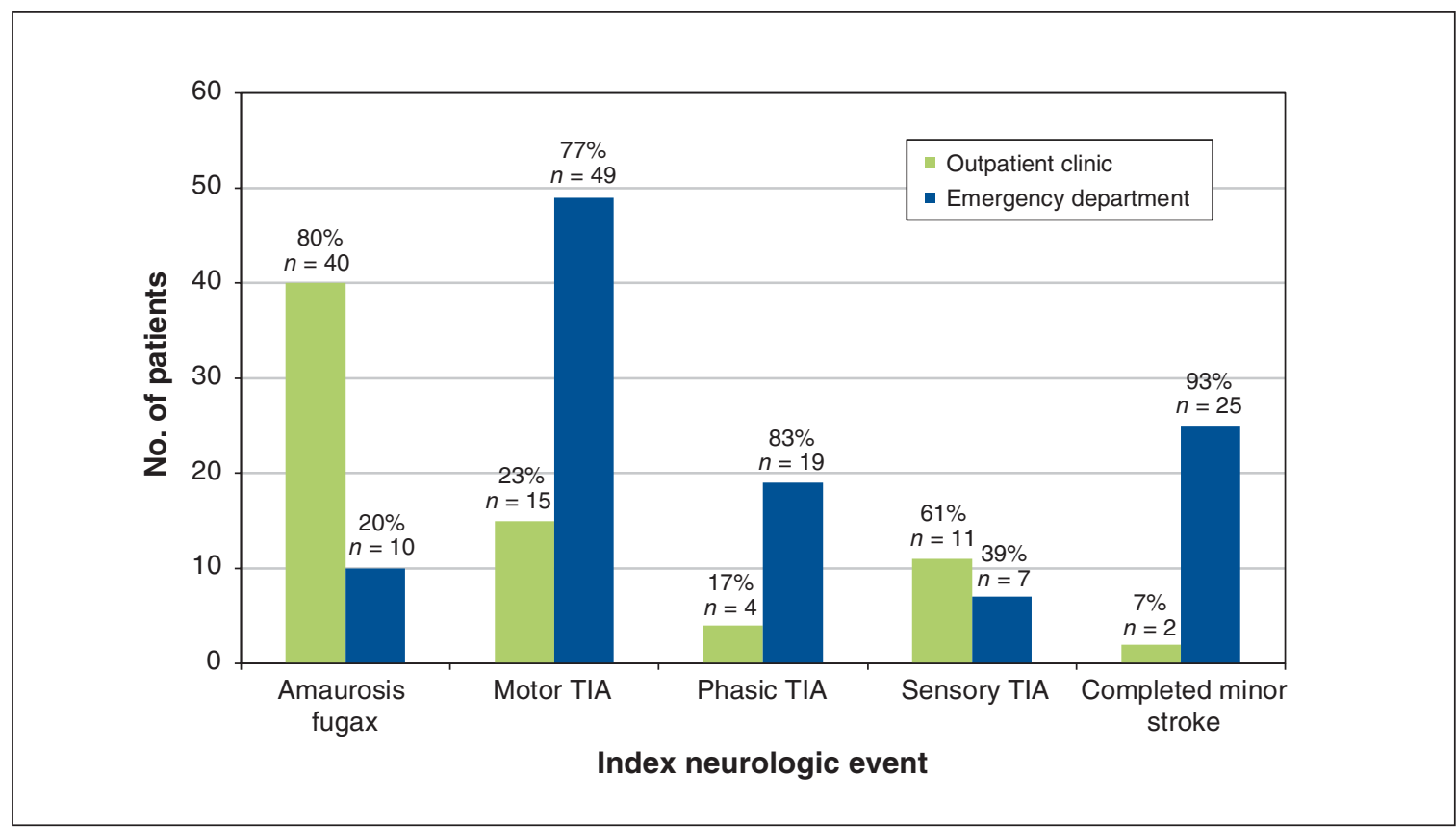

Figure 3: Presentation to outpatient clinic or emergency department by index neurologic event. Data on the location of first presentation were missing for some participants. Note: TIA = transient ischemic attack.

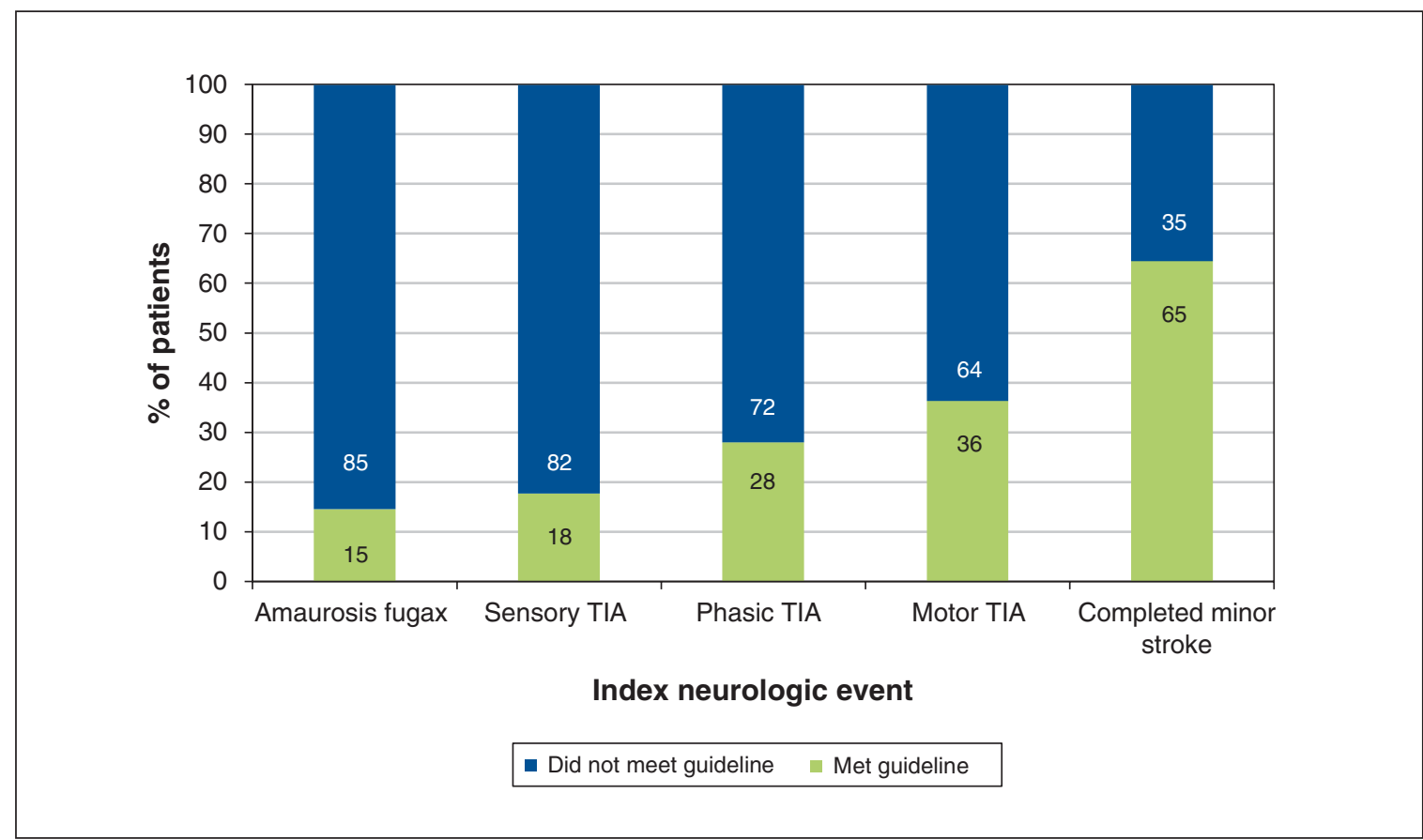

Figure 4: Proportion of patients who received surgery within 14 days of neurologic event, by index neurologic event. Note: $\mathrm{TIA}=$ transient ischemic attack.

0 days in the emergency department and 7.5 days in a nonemergency outpatient clinic setting $(p<0.001)$.

The patient's age, sex, place of residence (urban or rural) and city/town of first presentation were not associated with meeting the 14-day guideline, nor was the surgeon to whose care the patient presented. The duration of wait 2 did not vary among the 3 surgeons.

\section{Interpretation}

About one-third of our patients who experienced neurologic symptoms from severe (70\%-99\%) internal carotid artery stenosis underwent surgery within the recommended 14 days. We identified several factors that were associated with meeting this 14-day guideline. Delayed patient presentation was a significant 


\begin{tabular}{|c|c|c|c|}
\hline Comparison & $\begin{array}{l}\text { Explained } \\
\text { variance } \\
\left(\text { Cox-Snell } R^{2}\right)\end{array}$ & $\begin{array}{l}\text { Regression } \\
\text { coefficient } \\
\quad \pm \text { SE }\end{array}$ & OR $(95 \% \mathrm{Cl})$ \\
\hline Effect of surgeon & 0.05 & & \\
\hline Constant & & $-0.72 \pm 0.30$ & \\
\hline Surgeon $1-2$ & & $-0.48 \pm 0.48$ & $0.62(0.24-1.59)$ \\
\hline Surgeon $1-3$ & & $0.72 \pm 0.42$ & $2.06(0.90-4.71)$ \\
\hline Effect of all other variables & 0.29 & & \\
\hline Constant & & $-0.25 \pm 2.08$ & \\
\hline Age & & $-0.01 \pm 0.02$ & $0.99(0.94-1.04)$ \\
\hline Sex & & $-0.02 \pm 0.46$ & $0.98(0.40-2.39)$ \\
\hline City/town of residence & & $-0.62 \pm 0.46$ & $0.54(0.22-1.31)$ \\
\hline Clinical setting & & $2.21 \pm 0.66$ & $9.08(2.51-32.80)$ \\
\hline Index event $1-2 \dagger$ & & $-1.53 \pm 0.76$ & $0.22(0.05-0.96)$ \\
\hline Index event $1-3 \ddagger$ & & $-0.81 \pm 0.52$ & $0.44(0.16-1.24)$ \\
\hline \multicolumn{4}{|c|}{$\begin{array}{l}\text { Note: } \mathrm{Cl}=\text { confidence interval, } \mathrm{OR}=\text { odds ratio, } \mathrm{SE}=\text { standard error. } \\
{ }^{*} \text { The surgeon with the most cases was chosen as the base category to which the other surgeons were } \\
\text { compared. } \\
\text { tCompleted minor stroke - amaurosis fugax. } \\
\text { fCompleted minor stroke - motor transient ischemic attack. }\end{array}$} \\
\hline
\end{tabular}

factor, but we could not determine from our data whether this delay, attributable to wait 0 , was because patients failed to recognize the urgency of their symptoms and present promptly for care, or because of a lack of access to primary care services. There is likely a component of failure by patients to recognize the significance of minor neurologic events, as more severe symptoms were associated with patients' preferentially seeking emergency care through an emergency department.

Patients with dramatic index neurologic events were more likely than those with more subtle symptoms to receive timely surgery. One might consider 2 hypotheses to explain this observation. First, more dramatic hemispheric motor and phasic symptoms as well as index events causing a fixed neurologic deficit that can be identified on physical examination facilitate a more straightforward diagnostic path. Alternatively, subtler neurologic symptoms can be harder to diagnose and may lead to longer diagnostic paths, with a greater number of specialist consultations before the ultimate diagnosis is reached. This was not reflected in our data, however, because the number of consultants did not differ based on the presenting symptom. The health care system may simply provide speedier care, with preferential access to diagnostic tests and consultations, to patients with more dramatic presenting symptoms.

Our results are consistent with previous Canadian studies showing that the guideline of 14 days between the index neurologic event and carotid endarterectomy is achieved in less than half of patients. ${ }^{11,12,17}$ Both the current study and that of Jetty and colleagues ${ }^{11}$ revealed that delayed patient presentation, diagnosis and referral are significant factors resulting in a delay in definitive care. In both studies, patients with amaurosis fugax were less likely to meet the guideline, and those who presented to the emergency department were the most likely to meet the guideline. Jetty and colleagues ${ }^{11}$ showed that distance from the centre providing surgery was a significant factor in prompt surgery, but our study did not. Based on the statistical power of our study, we can exclude rurality as a major determinant in failure to receive timely surgery in our study population.

Previous research involving administrative data sets in Ontario showed that patients with a transient ischemic attack were more likely than those who experienced a stroke to meet the 14-day guideline. ${ }^{11}$ This may reflect a strategy of delayed surgery after stroke, used by some centres. A 1969 study on carotid revascularization suggested higher morbidity and mortality, including conversion of ischemic to hemorrhagic stroke, with early carotid endarterectomy, ${ }^{18}$ but more contemporary work showed the greatest benefit of surgery early after a minor neurologic event. ${ }^{19}$ We excluded from our study patients who had a major poststroke disability that required a period of neurologic recovery before surgery. We found that patients who presented with a completed minor stroke were most likely to undergo surgery within 14 days.

In a recent study by Charbonneau and colleagues, ${ }^{17} 39 \%$ of patients met the 14-day guideline following implementation of a centralized care system for cerebrovascular accidents. Those authors reported that $25 \%$ of their patients presented 14 days or more following the index neurologic event; the proportion in our study was $14 \%$. As in our study, presentation to an emergency department was significantly associated with reducing surgical delay on multivariable analysis.

Our findings are consistent with European research showing that patients with ischemic stroke undergo surgery faster 
than those with transient hemispheric or ocular symptoms, that patients with amaurosis fugax are the least likely to meet the 14-day guideline and that delayed patient presentation is significant. ${ }^{13}$ Some investigators have hypothesized that a "fast-track" referral system might ensure prompt treatment. ${ }^{11,12}$ This has been shown in a study from the United Kingdom, in which substantial decreases in the time from symptom to surgery were associated with the implementation of a fast-track system. ${ }^{20}$

\section{Limitations}

Our study was limited to a single centre experience. The retrospective nature of this study is also a limiting factor. Study inclusion was limited to patients who received carotid endarterectomy, and no data were available for those who may have been candidates for surgery but died or experienced a major stroke without surgery. In addition, the ICD-10-CA codes used in this study have not been validated. Last, our study did not address potentially important socioeconomic variables that may affect a patient's ability to attend appointments and influence wait 0 .

\section{Conclusion}

Targeted improvements might increase the proportion of patients receiving surgery within the recommended time frame. One such improvement should address patient recognition of the severity of symptoms and the need to present promptly to a practitioner. The Heart and Stroke Foundation of Canada's FAST (Face, Arms, Speech, Time) public awareness campaign strives for such public education on recognizing major symptoms of stroke,,$^{21}$ but subtle symptoms such as amaurosis fugax and sensory lateralizing symptoms, associated in our study with the greatest risk of delayed treatment, are not the focus of this campaign. The efficacy of a fast-track system of rapid referral, consultation and investigation of patients with appropriate focal neurologic symptoms has been shown elsewhere, and similar processes may help reduce treatment delays for patients with symptomatic severe internal carotid artery stenosis in the Canadian setting. Reducing treatment delays will be increasingly important, as recent best-practice guidelines recommend surgery within 48 hours of symptom onset in suitable patients. ${ }^{15}$

\section{References}

1. Moore WS, Hall A. Importance of emboli from carotid bifurcation in pathogenesis of cerebral ischemic attacks. Arch Surg 1970;101:708-11.

2. Age-standardized mortality rates by selected causes, by sex (both sexes). Ottawa: Statistics Canada [modified 2017]. Available: www.statcan.gc.ca/tables-tableaux/ sum-som/101/cst01/health30a-eng.htm (accessed 2018 May 9).

3. Barnett HJM, Taylor DW, Haynes RB, et al.; North American Symptomatic Carotid Endarterectomy Trial Collaborators. Beneficial effect of carotid endarterectomy in symptomatic patients with high-grade carotid stenosis. $N$ Engl 7 Med 1991;325:445-53.
4. Barnett HJM, Taylor DW, Eliasziw M, et al. Benefit of carotid endarterectomy in patients with symptomatic moderate or severe stenosis. North American Symptomatic Carotid Endarterectomy Trial Collaborators. N Engl 7 Med 1998;339:1415-25.

5. ECST Collaborative Group. Randomised trial of endarterectomy for recently symptomatic carotid stenosis: final results of the MRC European Carotid Surgery Trial (ECST). Lancet 1998;351:1379-87.

6. Fairhead JF, Mehta Z, Rothwell PM. Population-based study of delays in carotid imaging and surgery and the risk of recurrent stroke. Neurology 2005; 65:371-5.

7. Wu CM, McLaughlin K, Lorenzetie D, et al. Early risk of stroke after transient ischemic attack. Arch Intern Med 2007;167:2417-22.

8. Eliasziw M, Kennedy J, Hill M, et al. Early risk of stroke after a transient ischemic attack in patients with internal carotid artery disease. CMA7 2004;170:1105-9.

9. Rothwell PM, Eliasziw M, Gutnikov S, et al. Endarterectomy for symptomatic carotid stenosis in relation to clinical subgroups and timing of surgery. Lancet 2004;363:915-24.

10. Lindsay P, Bayley M, Hellings C, et al.; Canadian Stroke Strategy (a joint initiative of the Canadian Stroke Network and the Heart and Stroke Foundation of Canada). Canadian best practice recommendations for stroke care (updated 2008). CMA7 2008;179:S1-25.

11. Gladstone DJ, Oh J, Fang J, et al. Urgency of carotid endarterectomy for secondary stroke prevention: results from the registry of the Canadian Stroke Network. Stroke 2009;40:2776-82.

12. Jetty P, Husereau D, Kubelik D, et al. Wait times among patients with symptomatic carotid artery stenosis requiring carotid endarterectomy for stroke prevention. 7 Vasc Surg 2012;56:661-7.e1-2.

13. den Hartog AG, Moll FL, van der Worp HB, et al. Delay to carotid endarterectomy in patients with symptomatic carotid artery stenosis. Eur 7 Vasc Endovasc Surg 2014;47:233-9.

14. Moneta GL, Edwards JM, Chitwood RW, et al. Correlation of North American Symptomatic Carotid Endarterectomy Trial (NASCET) angiographic definition of $70 \%$ to $99 \%$ internal carotid artery stenosis with duplex scanning. 7 Vasc Surg 1993;17:152-7.

15. Coutts SB, Wein TH, Lindsay MP, et al. Canadian Stroke Best Practice Recommendations: secondary prevention of stroke guidelines, update 2014. Int 7 Stroke 2015;10:282-91.

16. Wright JG, Li K, Seguin C, et al. Development of pediatric wait time access targets. Can 7 Surg 2011;54:107-10.

17. Charbonneau P, Bonaventure P, Drudi L, et al. An institutional study of time delays for symptomatic carotid endarterectomy. 7 Vasc Surg 2016;64:1726-33.

18. Blaisdell WF, Clauss R, Galbraith J. Joint study of extracranial arterial occlusion. 7AMA 1969;209:1889-95.

19. De Rango P, Brown MM, Chaturvedi S, et al. Summary of evidence on early carotid intervention for recently symptomatic stenosis based on meta-analysis of current risks. Stroke 2015;46:3423-36.

20. Gaba KA, Syed MJB, Raza Z. Reducing the delay for carotid endarterectomy in South-East Scotland. Surgeon 2014;12:11-6.

21. Stroke: signs of stroke. Ottawa: Heart and Stroke Canada. Available: www. heartandstroke.ca/stroke/signs-of-stroke (accessed 2018 May 9).

Affiliations: College of Medicine (Meyer) and Department of Surgery (Kopriva), University of Saskatchewan; Departments of Research and Performance Support (Karreman) and Surgery (Kopriva), Regina Qu'Appelle Health Region, Regina, Sask.

Contributors: David Kopriva conceived the study. Daniel Meyer acquired the data. Daniel Meyer and David Kopriva contributed to the study design and to data analysis and interpretation, and drafted the manuscript. Erwin Karreman contributed to data analysis and interpretation. All of the authors critically revised the manuscript for important intellectual content, gave final approval of the version to be published and agreed to be accountable for all aspects of the work.

Meeting at which the data were presented in part: This work was presented at the Canadian Society for Vascular Surgery meeting, Sept. 16-17, Halifax.

Supplemental information: For reviewer comments and the original submission of this manuscript, please see www.cmajopen.ca/content/6/2/ E211/suppl/DC1. 